\title{
The prevalence and isolated subtypes of BK polyomavirus reactivation among patients infected with human immunodeficiency virus-1 in southeastern China
}

\author{
Caiqin $\mathrm{Hu}^{1}$ - Ying Huang ${ }^{1}$. Juwei Su${ }^{1} \cdot$ Mengyan Wang ${ }^{1}$. Qihui Zhou ${ }^{1} \cdot$ Biao Zhu ${ }^{1}$
}

Received: 26 July 2017 / Accepted: 18 December 2017 / Published online: 12 February 2018

(c) The Author(s) 2018. This article is an open access publication

\begin{abstract}
BK polyomavirus (BKPyV) is an opportunistic infectious pathogen that is associated with hemorrhagic cystitis and nephropathy, mainly in transplant recipients and human immunodeficiency virus 1 (HIV-1) infected patients. However, molecular characterization studies of BKPyV in China are rare. This study was designed to elucidate the prevalence and to determine the main subtypes of BKPyV among HIV-1-infected patients in southeastern China. In addition, the increased incidences for $\mathrm{BKPyV}$ reactivation were analyzed. The isolated BKPyV DNA was amplified by polymerase chain reaction (PCR) and the specimen sequences were aligned with the reference sequences for phylogenetic analysis. In this study, BKPyV viruria was detected in 64.2\% (88/137) of HIV-1-infected patients. Patients in the BKPyV-positive group were more diverse with respect to gender $(P=0.039)$ and age $(P=0.023)$ than their counterparts in the BKPy -negative group, and they had a higher rate of co-infection with tuberculosis $(\mathrm{TB})(P=0.026)$. Viruria was more commonly found in patients with CD4 counts $<200$ cells $/ \mathrm{mm}$ (72.7\%) than in those with CD4 counts $\geq 200$ cells $/ \mathrm{mm}$ (58.5\%) (not significant). All sequenced BKPyV isolates belonged to subtype I (13/32) and IV (19/32). A high prevalence of BKPyV reactivation was discovered in patients with HIV-1 infection. Females and elderly individuals, as well as those with a TB co-infection, appeared more susceptible to BKPyV reactivation in this study. BKPyV viruria was found more often and was associated with lower CD4 counts.
\end{abstract}

\begin{abstract}
Abbreviations
BKPyV BK polyomavirus

HIV-1 human immunodeficiency virus 1

HAART highly active antiretroviral therapy

TB Tuberculosis
\end{abstract}

Handling Editor: Marc H. V. Van Regenmortel.

Nucleotide sequence data are provided in the GenBank databases under the accession numbers MF522142-MF522173 corresponding to the detected nucleotide sequences ZHE-1 to ZHE-32.

Biao Zhu

zhubiao1207@zju.edu.cn

1 The Department of Infectious Diseases, State Key Laboratory for the Diagnosis and Treatment of Infectious Diseases, Collaborative Innovation Center for the Diagnosis and Treatment of Infectious Diseases, the First Affiliated Hospital, College of Medicine, Zhejiang University, Hangzhou, China

\section{Introduction}

The BK polyomavirus (BKPyV), a ubiquitous pathogen, is a member of the polyomaviridae family, originally isolated from the urine of a renal allograft recipient by Gardner SD in 1971 [1]. Approximately $90 \%$ of the human population is asymptomatically infected with the BKPyV during childhood. Afterwards, the primary infection virus remains latent [2-6]. In immunocompromised patients, BKPyV reactivation often causes ureteric stenosis and severe tubulointerstitial nephritis in post-transplant kidney patients and hemorrhagic cystitis in bone marrow transplant patients [7-12]. Human immunodeficiency virus 1 (HIV-1) patients are subject to other complications, such as meningitis, encephalitis, lymphoma, retinitis, syphilis, tuberculosis (TB), and pneumonia [7, 13-15].

Different BKPyV subtypes (I, II, III and IV) have been successfully detected in some countries, including Japan, Africa, the UK, Italy, the US, and other countries [2, 3, 7, 8, $14,16,17]$. The subtype I is further classified into subgroups $\mathrm{I} / \mathrm{a}, \mathrm{I} / \mathrm{b} 1, \mathrm{I} / \mathrm{b} 2$, and I/c, and subtype IV is further classified into subgroups IV/a $1, \mathrm{IV} / \mathrm{a} 2$, IV/b $1, \mathrm{IV} / \mathrm{b} 2$, IV/c 1 , and IV/c 2. Subtypes II and III are rarely found in the urine [3, 
8, 18-23]. Each of these subgroups harbors a unique geographic distribution: subtype I is widespread all over the world, while subtype IV is prevalent in East Asia [21, 24, 25].

There have been several studies of polyomavirus in immunocompetent adults and renal allograft recipients [3, $21,24,26]$. However, studies concerning BKPyV-reactivation among HIV-1 patients are still limited in China. For this reason, we carried out this study to investigate $\mathrm{BKPyV}$ reactivation and genotypes among Chinese HIV-1 patients. In order to investigate factors influencing BKPyV reactivation, the following data from patients were taken into consideration: gender, age, CD4+ T-cell levels, highly active antiretroviral therapy (HAART) initiation, and HIV-1-associated complications.

\section{Materials and methods}

\section{Study population}

A total of 137 HIV-1-infected patients from the Department of Infectious Disease of the First Affiliated Hospital of Zhejiang University were admitted to participate in the study. The cohort included 115 patients who were receiving HAART and 22 patients who were not being treated with antiretroviral therapy during enrollment in the study. We clearly explained the purpose of the study to each patient and obtained informed consent from all participants.

\section{DNA extraction, PCR, and sequence analysis}

At the beginning of the study, a midstream urine sample was collected from each patient. Ten milliliters of urine was divided into four centrifuge tubes, and each tube was centrifuged at $12,000 \mathrm{r} / \mathrm{min}$ for $10 \mathrm{~min}$; the supernatant was discarded, and the remaining urinary sediment was resuspended in $100 \mu \mathrm{l}$ sterile phosphate-buffered saline (PBS). Viral DNA was extracted with a QIAamp DNA Mini Kit (Sangon Biotech, Shanghai) in accordance with the manufacturer's instructions.

BKPyV DNA Primers were designed to be specific to the BKPyV VP1 fragment. The forward and the reverse primer sequences were as follows: 5'-GAAGTTCTAGAAGTTAAA ACTGGG-3' and 5'-CCTATTCAAGGCAGTAATTTCCAC $-3^{\prime}$, respectively $[16,19]$.

The target sequence was amplified in a reaction volume of $25 \mu \mathrm{L}$ containing $1 \mu \mathrm{L}$ of template, $2.5 \mu \mathrm{L}$ of $10 \times \mathrm{PCR}$ Buffer, each primer at a concentration of $10 \mu \mathrm{M}, 0.5 \mu \mathrm{L}$ of dNTPs, $2.5 \mu \mathrm{L}$ of $\mathrm{MgCl}_{2}$, and $2.5 \mathrm{U}$ of Taq polymerase per reaction.
The amplification parameters were as follows: DNA was denatured for $5 \mathrm{~min}$ at $95^{\circ} \mathrm{C}$, followed by 35 cycles of $95^{\circ} \mathrm{C}$ $(30 \mathrm{~s}), 55^{\circ} \mathrm{C}(35 \mathrm{~s})$, and $72^{\circ} \mathrm{C}(1 \mathrm{~min})$ and a final elongation step at $72^{\circ} \mathrm{C}$ for $8 \mathrm{~min}$. DNA sequencing was carried out using an automated sequencer (ABI 3730 gene analyzer DNA sequencer). The fragment obtained was $342 \mathrm{bp}$ in size.

\section{Phylogenetic analysis}

22 BKPyV whole-genome sequences were obtained from GenBank [20,25]. The accession numbers of the referenced sequences are shown in Table 1. Nucleotide sequence data from this study were added to the GenBank database under the accession numbers MF522142-MF522173, which corresponded to the detected nucleotide sequences ZHE-1 to ZHE-32.

Table 1 BKPyV reference sequences selected for phylogenetic analysis

\begin{tabular}{llll}
\hline $\begin{array}{l}\text { Subtype/ } \\
\text { subgroup }\end{array}$ & Isolate & Geographic origin & GenBank accession no. \\
\hline I/a & DUN & USA & NC_001538 \\
I/a & KEN-1 & Kenya & AB263926 \\
I/b1 & Dik & The Netherlands & AB211369 \\
I/b1 & WW & South Africa & AB211371 \\
I/b2 & JL & The Netherlands & AB211370 \\
I/b2 & FNL-12 & Finland & AB263918 \\
I/c & MT & Japan & AB211372 \\
I/c & TW-1 & Japan & AB211381 \\
II & ETH-3 & Ethiopia & AB263916 \\
II & SB & UK & Z19536 \\
III & AS & UK & M23122 \\
III & KOM-3 & Japan & AB211386 \\
IV/a1 & VNM-7 & Vietnam & AB269869 \\
IV/a1 & PHL-8 & Philippines & AB269859 \\
IV/a2 & MMR-1 & Myanmar & AB269841 \\
IV/b1 & THK-8 & Japan & AB211390 \\
IV/b1 & TW-3 & Japan & AB211391 \\
IV/b2 & KOM-2 & Japan & AB211387 \\
IV/b2 & JPN-15 & Japan & AB269834 \\
IV/c1 & MON-1 & Mongolia & AB269846 \\
IV/c1 & SWC-1 & China & AB269863 \\
IV/c2 & ITA-4 & Italy & AB269833 \\
\hline
\end{tabular}

A total of 55 sequences, including 32 covering the VP1 coding region of BKPyV DNA targeted in this study, $22 \mathrm{BKPyV}$ whole-genome sequences from GenBank and SA12, a baboon polyomavirus closely related to BKPyV [20, 25, 27-29]), were aligned and analyzed using BIOEDIT and MEGA software to construct a neighbor-joining (NJ) and Kimura 2-parameter model method tree. To determine the confidence level of the branching patterns in the tree, 1,000 bootstrap replicates were performed 


\section{Statistical analysis}

The independent samples non-parametric $t$-test was performed on numerical data, while chi-square test and Fisher's exact tests were carried out for the categorical variables. $P$-values of less than 0.05 were considered as statistically significant. All data were analyzed using SPSS software, version 23.0.

\section{Results}

\section{A high BKPyV reactivation rate in HIV-1-infected patients}

A total of $137 \mathrm{HIV}$-infected patients (16 women and 121 men) were enrolled in the study. The mean age was $39 \pm 13$ years old (Table 2). Regarding the level of immunity, the CD4+ T cell counts were divided into two groups: CD4 $<200, \geq 200$ cells $/ \mathrm{mm}^{3}$ and a clear divergence in median CD4 counts (48 vs. 397 cells $/ \mathrm{mm}^{3}$ ) within the BKPyV-positive and BKPyV-negative groups. An obvious difference was discovered in the interior group: there was $72.7 \% \mathrm{BKPyV}$ viruria present in the group with CD4 counts $<200$ cells/ $\mathrm{mm}^{3}$ and $58.5 \%$ where CD4 counts $\geq 200$ cells $/ \mathrm{mm}^{3}$.

As shown in Table 2, BKPyV viruria was detected in 88 HIV-1-infected patients (64.2\%). The BKPyV-positive excretion rate was higher in women than men $(87.5 \%$ vs. $61.2 \%$, respectively; $P=0.039$ ) and a direct correlation was revealed between age and BKPyV excretion $(P=0.023)$. BKPyV viruria was found in 16 of $22(72.7 \%)$ individuals who had not undergone antiretroviral therapy compared to 72 of 115 (62.6\%) of the HAART patients $(P=0.364)$. Coinfection with TB appeared linked to a higher susceptibility to $\mathrm{BKPyV}$ reactivation than other comorbidities, with an 85.7\% BKPyV excretion rate $(P=0.026)$ (Table 2$)$.

\section{Subtype IV is most prevalent in southeastern China}

Using genotyping and phylogenetic methods, 32 sequences were classified into four major clusters (I through IV), with the BP ranging from $89 \%$ (for subtype II) to $99 \%$ (for subtype IV) (Figure 1). Subtype I was further categorized into three sub-clusters: $\mathrm{I} / \mathrm{a}, \mathrm{I} / \mathrm{b}$, and $\mathrm{I} / \mathrm{c}$, with the BP ranging from $54 \%$ to $76 \%$. Concurrently, subtype IV was divided in to five subgroups: IV/a1, IV/a2, IV/b1, IV/b2, and IV/c. Overall, the present study demonstrated that subtype IV was the most common BKPyV subtype in southeastern China (19/32), with $15(46.88 \%)$ isolated sequences classified as IV-a and $4(12.5 \%)$ as IV-c. Subtype I ranked second-highest in prevalence (13/32), with $6(18.75 \%)$ isolated sequences classified as I-c and $7(21.87 \%)$ as I-b.
Table 2 Comparison of BKPyV excretion rates among HIV-infected patients

\begin{tabular}{|c|c|c|c|c|}
\hline Category & Total & $\begin{array}{l}\text { No. of } \\
\text { BKPyV } \\
\text { negatives }\end{array}$ & $\begin{array}{l}\text { No. of } \\
\text { BKPyV } \\
\text { positives }\end{array}$ & $P$-value \\
\hline Overall & 137 & $49(35.8)$ & $88(64.2)$ & \\
\hline Gender, n (\%) & & & & $0.039^{1}$ \\
\hline Male & 121 & $47(38.8)$ & $74(61.2)$ & \\
\hline Female & 16 & $2(12.5)$ & $14(87.5)$ & \\
\hline Age, years, n (\%) & & & & $0.023^{2}$ \\
\hline$\leq 20$ & 1 & $1(100)$ & $0(0.00)$ & \\
\hline $21-40$ & 88 & 34 (38.6) & $54(61.4)$ & \\
\hline $41-60$ & 35 & $12(34.3)$ & $23(65.7)$ & \\
\hline$>60$ & 13 & $2(15.4)$ & $11(84.6)$ & \\
\hline CD4+ cells/mm, n (\%) & & & & $0.089^{1}$ \\
\hline$<200$ & 55 & $15(27.3)$ & $40(72.7)$ & \\
\hline$\geq 200$ & 82 & $34(41.5)$ & $48(58.5)$ & \\
\hline \multicolumn{5}{|l|}{ Treatment, $\mathrm{n}(\%)$} \\
\hline Tenofovir & 61 & $21(34.4)$ & $40(65.6)$ & $0.769^{1}$ \\
\hline Zidovudine & 43 & $20(46.5)$ & $23(53.5)$ & $0.076^{1}$ \\
\hline Lamivudine & 111 & $42(37.8)$ & $69(62.2)$ & $0.296^{1}$ \\
\hline Efavirenz & 88 & $35(39.8)$ & $53(60.2)$ & $0.190^{1}$ \\
\hline \multicolumn{5}{|l|}{ Comorbidity, n (\%) } \\
\hline Hepatitis B & 8 & $3(37.5)$ & $5(62.5)$ & NS \\
\hline TB & 21 & $3(14.3)$ & $18(85.7)$ & $0.026^{1}$ \\
\hline Lymphoma & 6 & $2(33.3)$ & $4(66.6)$ & NS \\
\hline $\begin{array}{l}\text { Cryptococcal } \\
\text { meningitis }\end{array}$ & 9 & $5(55.6)$ & $4(44.4)$ & NS \\
\hline PCP & 6 & $3(50.0)$ & $3(50.0)$ & NS \\
\hline
\end{tabular}

1. Pearson Chi-Square, Continuity Correction and Fisher's exact test for categorical variables;

2. Independent samples $t$ test for numerical data

\section{Discussion}

Epidemiological data has shown that up to $90 \%$ of the human population is seropositive for BKPyV. After primary asymptomatic infection, $\mathrm{BKPyV}$ remains latent. However, low prevalence rates $(6 \%-40 \%)$ in immunocompetent children and adults have been reported in previous assays [5, $13,30,31]$. In this study, a high polyomavirus excretion rate (64.2\%), detected through BKPyV DNA, was identified in the urinary tract of HIV-1 patients. This high prevalence of polyomavirus indicates that $\mathrm{BKPyV}$ reactivation may be linked to the T cell immunodeficiency in HIV-1-infected patients.

$\mathrm{BKPyV}$ viruria was more common in females and elderly HIV-1-infected patients in this study ( $P$ values of 0.039 and 0.023 , respectively). These data are in contrast with previous studies that indicated that $\mathrm{BKPyV}$ excretion rates had no relationship with age or gender [5, 16, 30, 32, 33]. Meanwhile, we discovered that HIV-1 patients co-infected 
Fig. 1 Four subtypes of BKPyV identified by phylogenetic analysis. The phylogenetic tree was constructed using MEGA version 7.0.20. Bootstrap replicates were performed 1,000 times (only the numbers at nodes above 50 are shown). The types (I, II, III, and IV) and subtypes (IV-a1, IV-a2, IV-b1, IV-b2, IV-c, Ia, Ib, and Ic) are indicated

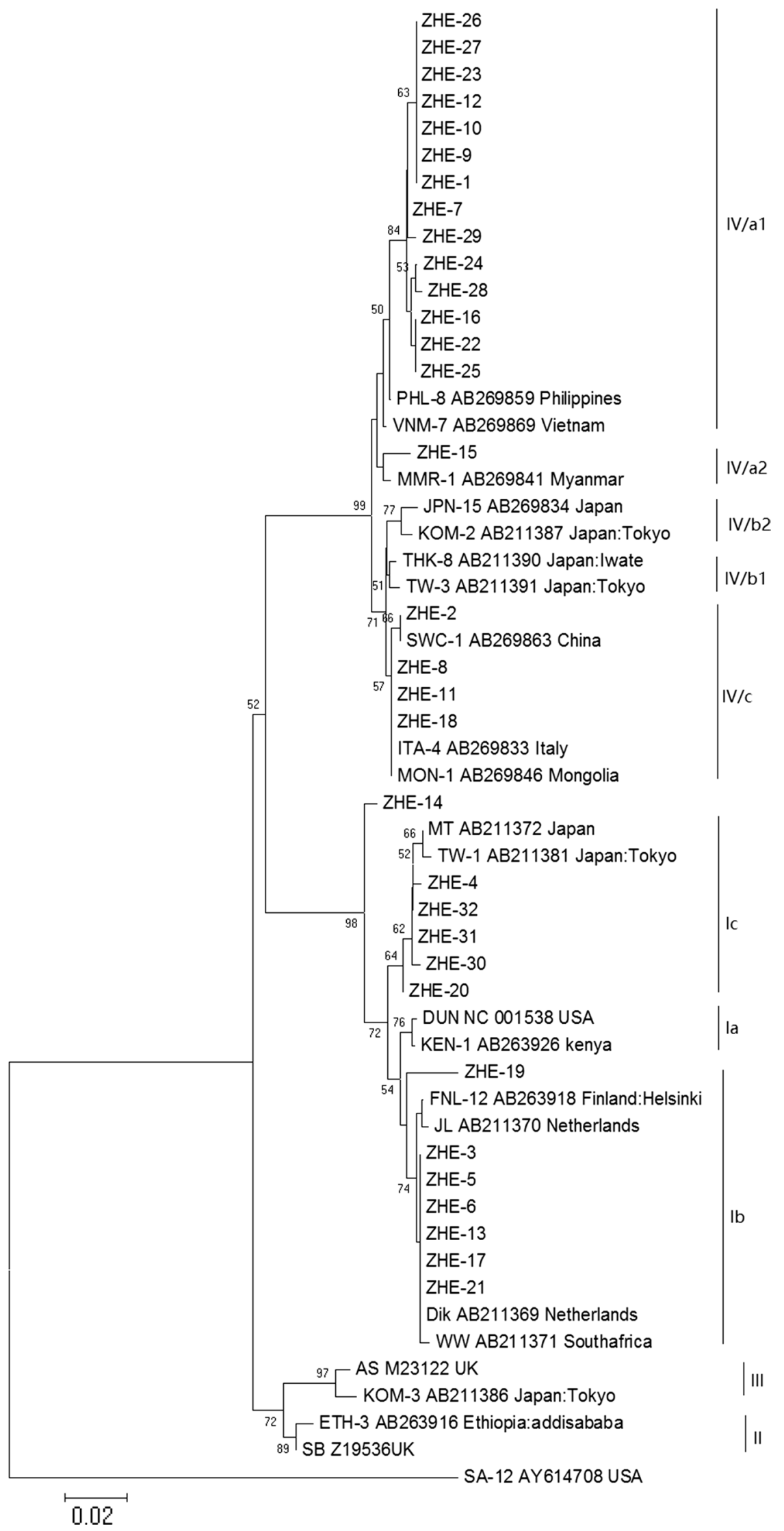


with TB were more susceptible to BKPyV reactivation $(P=$ $0.026)$. TB is not an uncommon disease to find in co-infections with HIV in developing countries, and a study by AlWarthan et al. indicated that polyomavirus nephropathy was reactivated with disseminated TB [14]. Increased BKPyV viruria was found in females, the elderly and individuals co-infected with TB. These results may only apply to this experiment due to specific demographic characteristics and the small population of patients.

BKPyV DNA was found in $58.5 \%$ of HIV-1-infected patients with CD4+counts $\geq 200$ cells $/ \mathrm{mm}^{3}$ and $72.7 \%$ of the patients with CD4+ counts $<200$ cells $/ \mathrm{mm}^{3}$. These results also revealed that higher $\mathrm{CD} 4$ counts corresponded to lower $\mathrm{BKPyV}$ viruria. However, there were no statistically significant associations between the presence of $\mathrm{BKPyV}$ in urine and the degree of immunodeficiency. Other investigators have also demonstrated increased BKPyV viruria with lower CD4 counts (not significant) $[2,17]$. Several reports have illustrated that BKPyV reactivation is closely associated with the elimination of virus-specific memory $\mathrm{T}$ cells and impairment of cell-mediated immune responses [33-37].

$\mathrm{BKPyV}$ isolates can be classified into four major subtypes based on molecular methods. In the present study, subtype IV was shown to be the most common BKPyV subtype in southeastern China (19/32), followed by subtype I (13/32). The majority of reports have found subtype I to be the most prevalent worldwide, while subtype IV is common in Asia and in parts of Europe [3, 21]. In China, a previous study reported that subtype I was found at the highest rate (63\%) and subtype IV at the second highest rate (37\%) in immunocompetent elderly patients in Shanghai [24]. Chen et al. also showed that $23 \mathrm{BKPyV}$ isolates (64\%) were classified as subtype I, and $13(36 \%)$ were classified as subtype IV in Chinese renal transplant patients [3]. All these results indicate a dominance of subtype I, which differs from the present article where subtype IV was dominant.

In conclusion, this is first study to evaluate the high reactivation rates and specific subtypes of BKPyV in HIV-1 patients in southeastern China. Our findings also indicated that being female, elderly, and co-infected with TB appeared to render HIV-1 patients more susceptible to BKPyV reactivation. BKPyV viruria was also found to be more closely associated with lower CD4 counts. It remains uncertain whether higher CD4 counts is associated with elimination of $\mathrm{BKPyV}$ viruria, therefore further study is needed to clarify this aspect of BKPyV persistence.

Acknowledgements We thank H.B. Wu and X.L. Peng (experts from the First Affiliated Hospital, Zhejiang University) for providing assistance with statistical analysis.

Funding This work was funded by the National Special Research Program for Important Infectious Diseases (No. 2014ZX10001002-002002; 2017ZX10202102-002-002).

\section{Compliance with ethical standards}

Conflict of interest All authors declare that there are no potential or actual competing interests and no financial or personal relationships with other people or organizations that could inappropriately influence their work.

Ethical approval All procedures performed in the study involving human participants were performed in accordance with the ethical standards of the Institutional Research Committee and with the 1964 Helsinki Declaration and its later amendments or comparable ethical standards.

Informed consent Informed consent was obtained from all individual participants included in the study.

Open Access This article is distributed under the terms of the Creative Commons Attribution 4.0 International License (http://creativeco mmons.org/licenses/by/4.0/), which permits unrestricted use, distribution, and reproduction in any medium, provided you give appropriate credit to the original author(s) and the source, provide a link to the Creative Commons license, and indicate if changes were made.

\section{References}

1. Gardner SD, Field AM, Coleman DV, Hulme B (1971) New human papovavirus (B.K.) isolated from urine after renal transplantation. Lancet 1:1253-1257. https://doi.org/10.1016/S0140 $-6736(71) 90562-9$

2. Behzad-Behbahani A, Klapper PE, Vallely PJ, Cleator GM, Khoo SH (2004) Detection of BK virus and JC virus DNA in urine samples from immunocompromised (HIV-infected) and immunocompetent (HIV-non-infected) patients using polymerase chain reaction and microplate hybridisation. J Clin Virol 29:224-229. https://doi.org/10.1016/S1386-6532(03)00155-0

3. Chen Q, Zheng HY, Zhong S, Ikegaya H et al (2006) Subtype IV of the BK polyomavirus is prevalent in East Asia. Arch Virol 151:2419-2429. https://doi.org/10.1007/s00705-006-0814-z

4. Sundsfjord A, Flaegstad T, Flo R, Spein AR, Pedersen M, Permin H, Julsrud J, Traavik T (1994) BK and JC viruses in human immunodeficiency virus type 1-infected persons: prevalence, excretion, viremia, and viral regulatory regions. J Infect Dis 169:485-490. https://doi.org/10.1093/infdis/169.3.485

5. Knowles WA, Pillay D, Johnson MA, Hand JF, Brown DW (1999) Prevalence of long-term BK and JC excretion in HIV-infected adults and lack of correlation with serological markers. J Med Virol 59:474-479. doi:10.1002/(SICI)10969071(199912)59:4\%3c474:AID-JMV9\%3e3.0.CO;2-W

6. Chung BH, Hong YA, Kim HG, Sun IO, Choi SR et al (2012) Clinical usefulness of BK virus plasma quantitative PCR to prevent BK virus associated nephropathy. Transpl Int 25:687-695. https://doi.org/10.1111/j.1432-2277.2012.01480.x

7. Agostini HT, Brubaker GR, Shao J, Levin A, Ryschkewitsch CF, Blattner WA, Stoner GL (1995) BK virus and a new type of JC virus excreted by HIV-1 positive patients in rural Tanzania. Arch Virol 140:1919-1934. https://doi.org/10.1007/BF01322682

8. Di Taranto C, Pietropaolo V, Orsi GB, Jin L, Sinibaldi L, Degener AM (1997) Detection of BK polyomavirus genotypes in healthy and HIV-positive children. Eur J Epidemiol 13:653-657. https:// doi.org/10.1007/BF01322682

9. Chen Y, Sharp PM, Fowkes M, Kocher O, Joseph JT, Koralnik IJ (2004) Analysis of 15 novel full-length BK virus sequences from 
three individuals: evidence of a high intra-strain genetic diversity. J Gen Virol 85:2651-2663. https://doi.org/10.1099/vir.0.79920-0

10. Miller AN, Glode A, Hogan KR, Schaub C, Kramer C, Stuart RK, Costa LJ (2011) Efficacy and safety of ciprofloxacin for prophylaxis of polyomavirus BK virus-associated hemorrhagic cystitis in allogeneic hematopoietic stem cell transplantation recipients. Biol Blood Marrow Transplant 17:1176-1181. https ://doi.org/10.1016/j.bbmt.2010.12.700

11. Broekema NM, Abend JR, Bennett SM, Butel JS, Vanchiere JA, Imperiale MJ (2010) A system for the analysis of BKV non-coding control regions: application to clinical isolates from an HIV/ AIDS patient. Virology 407:368-373. https://doi.org/10.1016/j. virol.2010.08.032

12. Satyanarayana G, Marty FM, Tan CS (2014) The polyomavirus puzzle: is host immune response beneficial in controlling BK virus after adult hematopoietic cell transplantion? Transpl Infect Dis 16:521-531. https://doi.org/10.1111/tid.12233

13. Karalic D, Lazarevic I, Banko A, Cupic M, Jevtovic D, Jovanovic T (2016) Molecular characterization of BK virus in patients infected with human immunodeficiency virus. Med Microbiol Immunol 205:185-193. https://doi.org/10.1007/s00430-015-0439-5

14. Al-Warthan S, Al-Hwiesh A (2014) Co-existence of BKV nephropathy and disseminated tuberculosis in transplant recipient. Saudi J Kidney Dis Transpl 25:1046-1050. https://doi. org/10.4103/1319-2442.139936

15. Engels EA, Rollison DE, Hartge P, Baris D, Cerhan JR, Severson RK et al (2005) Antibodies to JC and BK viruses among persons with non-Hodgkin lymphoma. Int J Cancer 117:1013-1019. https ://doi.org/10.4103/1319-2442.139936

16. Nali LH, Cristiane CU, Paulo RPP, Augusto CV, Jose EM, Erique PP, Claudio SF, Maria CD (2012) High prevalence of the simultaneous excretion of polyomaviruses JC and BK in the urine of HIVinfected patients without neurological symptoms in São Paulo, Brazil. Revista do Instituto de Medicina Tropical de São Paulo 54:201-205. https://doi.org/10.1590/s0036-46652012000400004

17. Akhgari S, Mohraz M, Azadmanesh K, Vahabpour R, Kazemimanesh M, Aghakhani A et al (2016) Frequency and subtype of BK virus infection in Iranian patients infected with HIV. Med Microbiol Immunol 205:57-62. https://doi.org/10.1007/s0043 0-015-0426-X

18. Wang ZY, Hong WL, Zhu ZH, Chen YH, Ye WL, Chu GY, Li JL, Chen BC, Xia P (2015) Phylogenetic reconstruction and polymorphism analysis of BK virus VP2 gene isolated from renal transplant recipients in China. Exp Ther Med 10:1759-1767. https ://doi.org/10.3892/etm.2015.2723

19. Krumbholz A, Zell R, Egerer R, Sauerbrei A, Helming A, Gruhn B, Wutzler P (2006) Prevalence of BK virus subtype I in Germany. J Med Virol 78:1588-1598. https://doi.org/10.1002/jmv.20743

20. Nishimoto Y, Takasaka T, Hasegawa M, Zheng HY, Chen Q, Sugimoto C, Kitamura T, Yogo Y (2006) Evolution of BK virus based on complete genome data. J Mol Evol 63:341-352. https://doi. org/10.1007/s00239-005-0092-5

21. Nishimoto Y, Zheng HY, Zhong S, Ikegaya H, Chen Q, Sugimoto C, Kitamura T, Yogo Y (2007) An Asian origin for subtype IV BK virus based on phylogenetic analysis. J Mol Evol 65:103-111. https://doi.org/10.1007/s00239-006-0269-6

22. Zhong S, Randhawa PS, Ikegaya H, Chen Q, Zheng HY, Suzuki M, Takeuchi T, Shibuya A, Kitamura T, Yogo Y (2009) Distribution patterns of BK polyomavirus (BKV) subtypes and subgroups in American, European and Asian populations suggest co-migration of BKV and the human race. J Gen Virol 90:144152. https://doi.org/10.1099/vir.0.83611-0

23. Boukoum H, Nahdi I, Foulongne V, Zallema D, Aloui S, Achour A, Segondy M, Aouni M (2011) Distribution of BK polyomavirus genotypes in Tunisian renal transplant recipients. J Med Virol 83:725-730. https://doi.org/10.1002/jmv.22035

24. Zhong S, Jeong BH, Ikegaya H, Kim YS, Xu Y, Zhu M, Chao $Y$ et al (2009) Comparison of the distribution patterns of BK polyomavirus lineages among China, Korea and Japan: implications for human migrations in northeast Asia. Microbiol Immunol 53:266-276. https://doi.org/10.1111/j.1348-0421.2009.00121.x

25. Zheng HY, Nishimoto Y, Chen Q, Hasegawa M, Zhong S, Ikegaya $\mathrm{H}$ et al (2007) Relationships between BK virus lineages and human populations. Microbes Infect 9:204-213. https://doi. org/10.1016/j.micinf.2006.11.008

26. Sugimoto C, Hara K, Taguchi F, Yogo Y (1989) Growth efficiency of naturally occurring BK virus variants in vivo and in vitro. $J$ Virol 63:3195-3199

27. Tavis JE, Walker DL, Gardner SD, Frisque RJ (1989) Nucleotidesequence of the human polyomavirus as virus, an antigenic variant of Bk virus. J Virol 63:901-911

28. Seif I, Khoury G, Dhar R (1979) The genome of human papovavirus BKV. Cell 18:963-977. https://doi.org/10.1016/00928674(79)90209-5

29. Jin L, Gibson PE, Knowles W, AClewley JP (1993) BK virus antigenic variants: sequence analysis within the capsid VP1 epitope. J Med Virol 39:50-56. https://doi.org/10.1002/jmv.1890390110

30. Karalic D, Lazarevic I, Cupic M, Jevtovic D, Jovanovic T (2014) Prevalence of JC and BK polyomavirus excretion in the urine of HIV-infected patients from Serbia. Arch Biol Sci 66:609-614. https://doi.org/10.2298/ABS1402609K

31. Boukoum H, Nahdi I, Sahtout W, Skiri H, Segondy M, Aouni $\mathrm{M}$ (2106) BK and JC virus infections in healthy patients compared to kidney transplant recipients in Tunisia. Microb Pathog 97:204-208. https://doi.org/10.1016/j.micpath.2016.06.015

32. Machado DM, Fink MC, Pannuti CS, Succi RC, Machado AA et al (2011) Human polyomaviruses JC and BK in the urine of Brazilian children and adolescents vertically infected by HIV. Mem Inst Oswaldo Cruz 106:931-935. https://doi.org/10.1590/ S0074-02762011000800006

33. Ledesma J, Munoz P, Garcia de Viedma D, Cabrero I, Loeches B et al (2012) BK virus infection in human immunodeficiency virusinfected patients. Eur J Clin Microbiol Infect Dis 31:1531-1535. https://doi.org/10.1007/s10096-011-1474-9

34. Mani J, Jin N, Schmitt M (2014) Cellular immunotherapy for patients with reactivation of JC and BK polyomaviruses after transplantation. Cytotherapy 16:1325-1335. https://doi. org/10.1016/j.jcyt.2014.04.003

35. Sharma R, Tzetzo S, Patel S, Zachariah M, Sharma S, Melendy T, Sharma R (2016) BK virus in kidney transplant: current concepts, recent advances, and future directions. Exp Clin Transplant 14:377-384. https://doi.org/10.6002/ect.2016.0030

36. Kaneko T, Moriyama T, Tsubakihara Y, Horio M, Imai E (2005) Prevalence of human polyoma virus (BK virus and JC virus) infection in patients with chronic renal disease. Clin Exp Nephrol 9:132-137. https://doi.org/10.1111/j.1399-3062.2011.00614.x

37. Nickeleit V, Singh HK (2015) Polyomaviruses and disease: is there more to know than viremia and viruria? Curr Opin Organ Transplant 20:348-358. https://doi.org/10.1097/MOT.00000 00000000192 